\title{
Anterior Chest Wall Involvement in Early Stages of Spondyloarthritis: Advanced Diagnostic Tools
}

\author{
ROBERTA RAMONDA, MARIAGRAZIA LORENZIN, ALESSANDRO LO NIGRO, STEFANIA VIO, \\ PIETRO ZUCCHETTA, PAOLA FRALLONARDO, CARLA CAMPANA, FRANCESCA OLIVIERO, \\ VALENTINA MODESTI, and LEONARDO PUNZI
}

\begin{abstract}
Objective. Anterior chest wall (ACW) involvement is difficult to evaluate in patients with spondyloarthritis (SpA). Bone scan is sensitive to ACW involvement, while magnetic resonance imaging (MRI) detects early alterations in SpA. We compared the sensitivity and specificity of bone scans and MRI in assessing ACW in early SpA.

Methods. Out of 110 patients with early SpA attending the Outpatient Rheumatology Unit Clinic of Padua University from January 2008 to December 2010, the 40 complaining of pain and/or tenderness [60\% with psoriatic arthritis (PsA), $12.5 \%$ with ankylosing spondylitis, and $27.5 \%$ with undifferentiated SpA] underwent bone scans and MRI.

Results. At clinical examination, sternocostoclavicular joints were involved in $87.5 \%$ on the right, $77.5 \%$ on the left, and $35 \%$ on the sternum. Bone scan was positive in $100 \%$ and MRI in $62.5 \%$ of these patients. Early MRI signs (bone edema, synovial hyperemia) were observed in $27.5 \%$, swelling in $5 \%$, capsular structure thickness in $37.5 \%$, erosions in $15 \%$, bone irregularities in $15 \%$, osteoproductive processes in $12.5 \%$, and osteophytes in 5\%. A higher prevalence of $\mathrm{Cw} 6, \mathrm{Cw} 7, \mathrm{~B} 35$, and $\mathrm{B} 38$ was found in $15 \%, 48 \%, 28 \%$, and $12 \%$, respectively, of the patients with PsA who had bone scans.

Conclusion. Noted mainly in women, ACW involvement was frequent in early SpA. Both bone scans and MRI are useful in investigating ACW inflammation. Bone scans were found to have high sensitivity in revealing subclinical involvement, but a low specificity. MRI provides useful information for therapeutic decision making because it reveals the type and extent of the process. The significant associations of HLA-Cw6 and Cw7 with PsA could suggest that genetic factors influence ACW involvement. (First Release July 15 2012; J Rheumatol 2012;39:1844-9; doi:10.3899/jrheum.120107)
\end{abstract}

Key Indexing Terms:

ANTERIOR CHEST WALL SPONDYLOARTHRITIS MRI BONE SCAN

Timely therapeutic intervention before stable anatomical damage is established has become an important goal for rheumatologists. An optimal outcome can be expected when the diagnosis is made early and the affected site is localized and treated. Involvement of anterior chest wall (ACW), in particular of sternocostoclavicular joints (SCCJ), sternocostal joints (SCJ), the manubriosternal joint, and the third inferior medial portion of the sternum, has been reported in patients with spondyloarthritis $(\mathrm{SpA})^{1,2,3,4}$. Its frequency and severity have been underestimated, mainly owing to the difficulty in determining the origin of pain during examination, because a wide variety

From the Rheumatology Unit, Department of Clinical and Experimental Medicine, University of Padua; and Department of Radiology 1 and Department of Nuclear Medicine 1, Padua Hospital, Padua, Italy.

R. Ramonda, MD, PhD; M. Lorenzin, MD; A. Lo Nigro, MD, PhD, Rheumatology Unit, Department of Clinical and Experimental Medicine, University of Padua; S. Vio, MD, Department of Radiology 1, Padua Hospital; P. Zucchetta, MD, Department of Nuclear Medicine 1, Padua Hospital; P. Frallonardo, MD; C. Campana, MD; F. Oliviero, PhD; V. Modesti, MD; L. Punzi, MD, PhD, Rheumatology Unit, Department of Clinical and Experimental Medicine, University of Padua.

Address correspondence to Dr. R. Ramonda, Rheumatology Unit,

Department of Clinical and Experimental Medicine, University of Padua,

Via Giustiniani 2, 35128 Padua, Italy.E-mail roberta.ramonda@unipd.it

Accepted for publication May 10, 2012. of extraarticular disorders are possible in this anatomic region ${ }^{1}$. Conventional radiography is of limited value because uniplanar imaging of ACW joints has low sensitivity to initial pathological alterations $5,6,7,8$. Bone scanning has been found to be very sensitive in these cases, although its specificity as a diagnostic procedure is considered low $4,5,6,7,8,9$. Magnetic resonance imaging (MRI) appears to be more effective in assessing initial pathological processes in the early stages of $\mathrm{SpA}^{10,11,12,13,14}$

The aim of our study was to compare the reliability of these 2 methods in assessing ACW involvement in patients who have been diagnosed with SpA within 1 year, defined as "early SpA." Another aim was to study the prevalence of ACW involvement in these patients and to ascertain which joints are most frequently involved, and the frequency of human leukocyte antigen (HLA). Studies have reported a correlation between the frequency of ACW involvement and the course and the severity of $\mathrm{SpA}^{15,16,17,18}$, and more recent data suggest that it is often the first symptom of the disease in undifferentiated $\mathrm{SpA}(\mathrm{uSpA})^{4,9,19,20}$.

\section{MATERIALS AND METHODS}

Patients. One hundred ten consecutive outpatients with early stages of SpA attending the Early Arthritis Clinic of the Rheumatology Unit of the

Personal non-commercial use only. The Journal of Rheumatology Copyright @ 2012. All rights reserved. 
University of Padua Medical Center between January 2008 and December 2010 were evaluated for study. Forty who complained of pain and/or tenderness in ACW joints ( 22 women, mean age $46.5 \pm 13.3$ yrs) were enrolled. Approval by the local Ethics Committee was obtained and all subjects gave written informed consent.

Inclusion criteria. The inclusion criteria were recent diagnosis of $\mathrm{SpA}(<1$ year), in accord with the European Spondylarthropathy Study Group classification $^{21}$, and presence of pain and/or tenderness in ACW joints during assessment.

Exclusion criteria. The exclusion criteria were as follows: SpA diagnosis established > 1 year previously; use of disease-modifying antirheumatic drugs, antitumor necrosis factor- $\alpha$ agents, or nonsteroidal antiinflammatory drugs before enrollment; or concomitant presence of other diseases potentially causing clinical involvement of ACW.

Clinical assessment. During the physical examination the patient was questioned about age, time of onset, and characteristics of joint symptoms, site of pain or discomfort, and family history of arthritis and/or psoriasis and other comorbidities. After the patient's medical history was evaluated by double-blinded trained rheumatologists, the number of tender/swollen joints was assessed using the American College of Rheumatology joint count (clinical evaluation scale of 44 joints). The right and left SCCJ (Figure 1), SCJ, sternal joint, and the inferior medial third of the sternum were also evaluated for presence/absence of spontaneous pain, pain evoked by digital pressure, swelling, and redness of skin.

The Bath Ankylosing Spondylitis Disease Activity Index and Bath Ankylosing Spondylitis Functional Index, the visual analog scale (VAS) for pain, the VAS for patient global health, and the Health Assessment Questionnaire (HAQ) were administered to all patients.

The 40 patients with pain and/or tenderness in ACW joints all underwent the following laboratory and instrumental assessments.

Laboratory assessments. Erythrocyte sedimentation rate and C-reactive protein were determined, along with HLA-A, -B, and -C (complement-dependent microlymphocytic assay).

Total-body bone scintigraphy. Total-body bone scintigraphy was performed at the Nuclear Medicine Service of the University of Padua. All 40 patients received a $740-\mathrm{MBq}$ injection of $99 \mathrm{~m}-\mathrm{Tc}-\mathrm{methylene}$ diphosphonate. Scintigraphic images were classified as positive or negative on the basis of the hypercaptation areas observed (Figure 2A).

MRI of anterior chest wall. MRI scanning was performed at the Radiology Service of the University of Padua to investigate underlying joint alterations during early disease phases (bony edema, synovial hyperemia, swelling, increase of thickness of capsular structure; Figure 2B) or advanced damage (bone sclerosis, hyperostotic process with osteophytes, erosions, ankylosis). Images were acquired in the sagittal and coronal planes with patients in prone or supine position (images were acquired during the expiration phase).

All MRI scans were performed using a 1.0-T unit equipped with a phased-array surface coil (Magnetom Harmony, Siemens AG Medical Solutions, Munich, Germany). MRI images were obtained without using tracer. All images were evaluated by double-blinded trained radiologists.

Statistical assessment. Kappa values were used to estimate agreement between clinical findings and the imaging results for each ACW joint site.

\section{RESULTS}

Forty (34\%) of the 110 patients complained of pain and/or tenderness during the clinical assessment. Of these, $60 \%$ were diagnosed with PsA, $12.5 \%$ with ankylosing spondylitis (AS), and $27.5 \%$ with uSpA; $67.5 \%$ had axial/peripheral, $15 \%$ axial, and $17.5 \%$ peripheral involvement. Patients' demographic and clinical data including the results of questionnaires evaluating functional status and the distribution of inflammatory markers are outlined in Table 1.

On examination, we found spontaneous pain and/or swelling and/or skin redness and/or digital pressure reaction indicating right SCCJ involvement in $87.5 \%$ of patients, left SCCJ involvement in $77.5 \%$, SCJ involvement in $20 \%$, sternal joint involvement in $35 \%$, and sternal involvement in $10 \%$

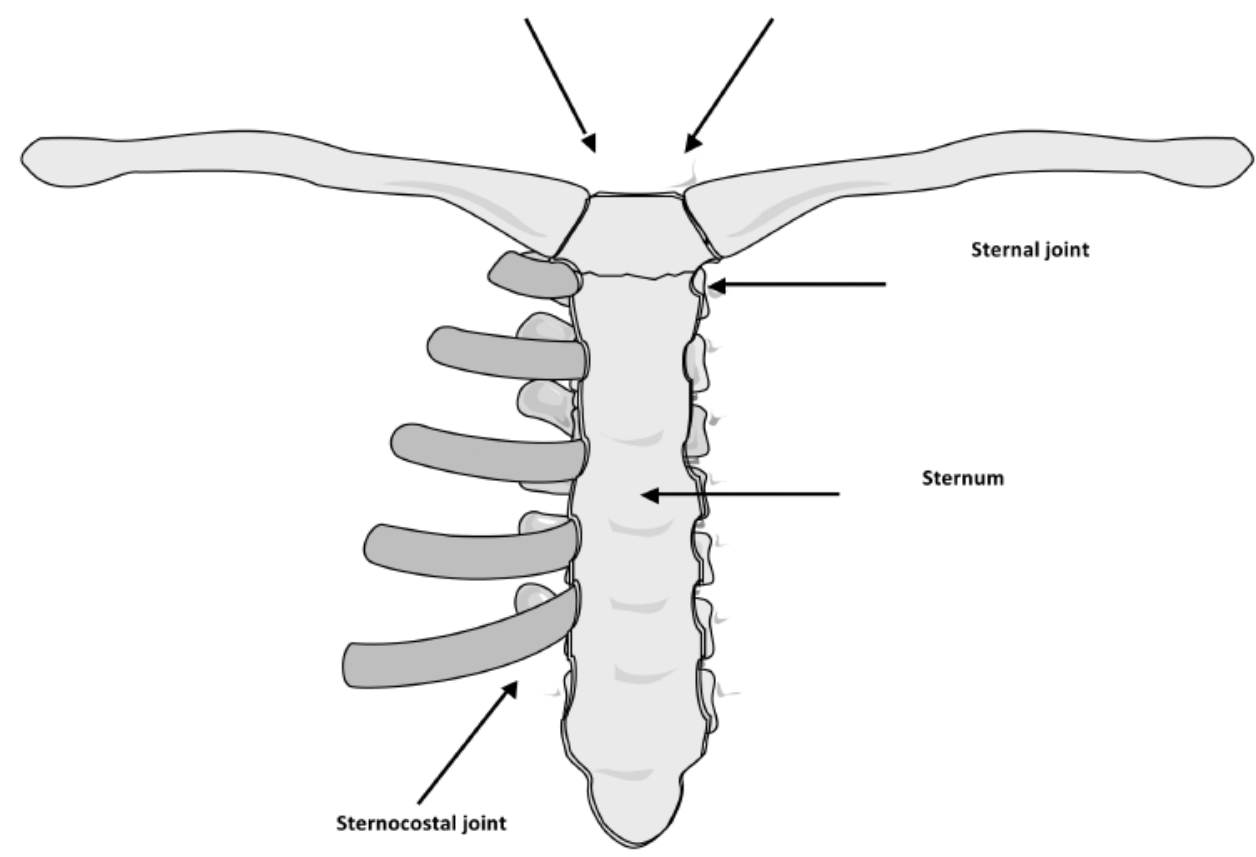

Figure 1. Anatomy of the anterior chest wall. SCCJ: sternocostoclavicular joint. 


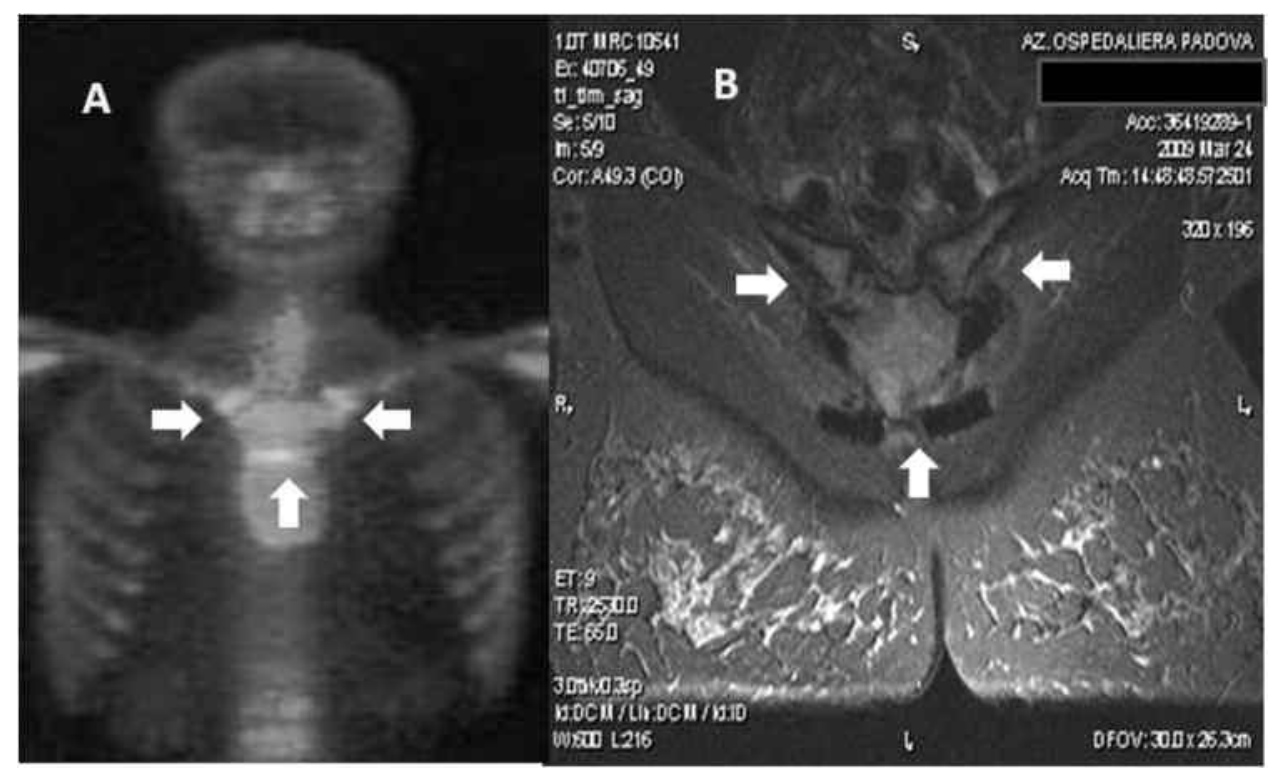

Figure 2. A. Bone scan shows sternocostoclavicular joint (SCCJ) and manubriosternal joint hypercaptation (arrows). B. T2 magnetic resonance imaging sequence shows bone edema of SCCJ (arrows).

(Figure 3). A bone scan result was positive in all patients: in the right SCCJ in $67.5 \%$, in the left SCCJ in $52.5 \%$, in the sternal joint in $35 \%$, in the SCJ in $22.5 \%$, and in the sternum in $12.5 \%$.

MRI result was normal in $37.5 \%$, while it revealed pathologic findings of inflammatory processes in $62.5 \%$. In SCCJ, MRI showed involvement respectively in the right and left in $47.0 \%$ and $40.0 \%$, while both the sternal joint and sternum were affected in $20 \%$ of patients. The main pathological alterations on MRI scans were signs of active disease - bone edema and/or synovial hyperemia in $27.5 \%$, swelling in 5\%, and increased capsular structure thickness in $37.5 \%$; and findings of advanced damage - erosion in $15 \%$, bone irregularities in $15 \%$, osteoproductive process in $12.5 \%$, and osteophytes in $5 \%$.

Immunogenetic HLA assessment was also performed. HLA-B27 was found in 58\% of the bone scan-negative patients and in $20 \%$ of MRI-negative patients. A higher prevalence of $\mathrm{Cw} 6, \mathrm{Cw} 7, \mathrm{~B} 35$, and $\mathrm{B} 38$ was found, respectively, in $15 \%, 48 \%, 28 \%$, and $12 \%$ of bone scan-positive patients. A higher prevalence of $\mathrm{Cw} 7$ and $\mathrm{B} 38$ alleles was found, respectively, in 53\% and $12 \%$ of the MRI-positive patients; the same alleles were found in $44 \%$ and in $0 \%$ of MRI-negative patients. That $\mathrm{Cw} 7$ was prevalent in PsA patients with positive bone scans $(30 \%)$ was considered an interesting finding, and this was also confirmed in patients with PsA who were MRI-positive (18\%); a frequent prevalence of Cw6 in the bone scan-positive PsA group (10\%) was similarly noted. Details of HLA antigens found in our patients are outlined in Table 1.

Findings from the patients' clinical evaluations and bone scan and MRI data are outlined in Table 2.

Data for clinical findings and imaging results in ACW joints are described in Table 3 .

\section{DISCUSSION}

Prevalence and type of involvement of the ACW in the early stages of SpA have not been clearly defined in clinical practice $^{1,2}$. Out of 110 patients with recently diagnosed SpA attending our clinic, 40 subjects (36.4\%) qualified for study because they manifested at least 1 symptom (pain or tenderness) in ACW joints. All these patients underwent bone scan and MRI testing and all were found to be bone scan-positive for at least $1 \mathrm{ACW}$ joint site. As in a previous study $\mathrm{y}^{4,9}$, a bone scan in patients with PsA was found to be sensitive to subclinical lesions. The prevalence of ACW involvement was found to be different in the various SpA subsets. Active clinical signs such as pain or tenderness and bone scan positivity were, indeed, more frequent in the group with PsA $(60 \%)$ than in the AS (12.5\%) group, but prevalence in the 2 groups was similar: $15 \%$ in PsA and $17 \%$ in AS, as described ${ }^{1}$. However, Weber, et al recently reported that signs of ACW inflammation prevalently occurred in $\mathrm{AS}$ rather than in $\mathrm{uSpA}^{22}$.

With regard to HLA typing, it was interesting that bone scanning gave a positive result in SpA patients with Cw6 and B38, while it was negatively associated with B27. There was, moreover, a higher prevalence of $\mathrm{Cw} 7$ and $\mathrm{B} 38$ alleles in the MRI-positive patients, while MRI was negative in the SpA patients with HLA-B27. That $\mathrm{Cw} 7$ was observed in bone scan-positive and MRI-positive patients with PsA (respectively in $30 \%$ and $18 \%$ ) was considered an important finding, as was the high prevalence of $\mathrm{Cw} 6$ in bone scan-positive patients with PsA (10\%). These results could be related to the higher prevalence of SpA in the patients studied and particularly in the PsA group. The significant association of HLA-Cw6 and Cw7 with PsA highlights the importance of genetic factors ${ }^{23}$, which could play a pathogenic role in clinical manifestations and may represent a risk factor for ACW joint inflammation. 
Table 1. Main demographic and clinical characteristics, biomarkers, and functional data in patients with SpA.

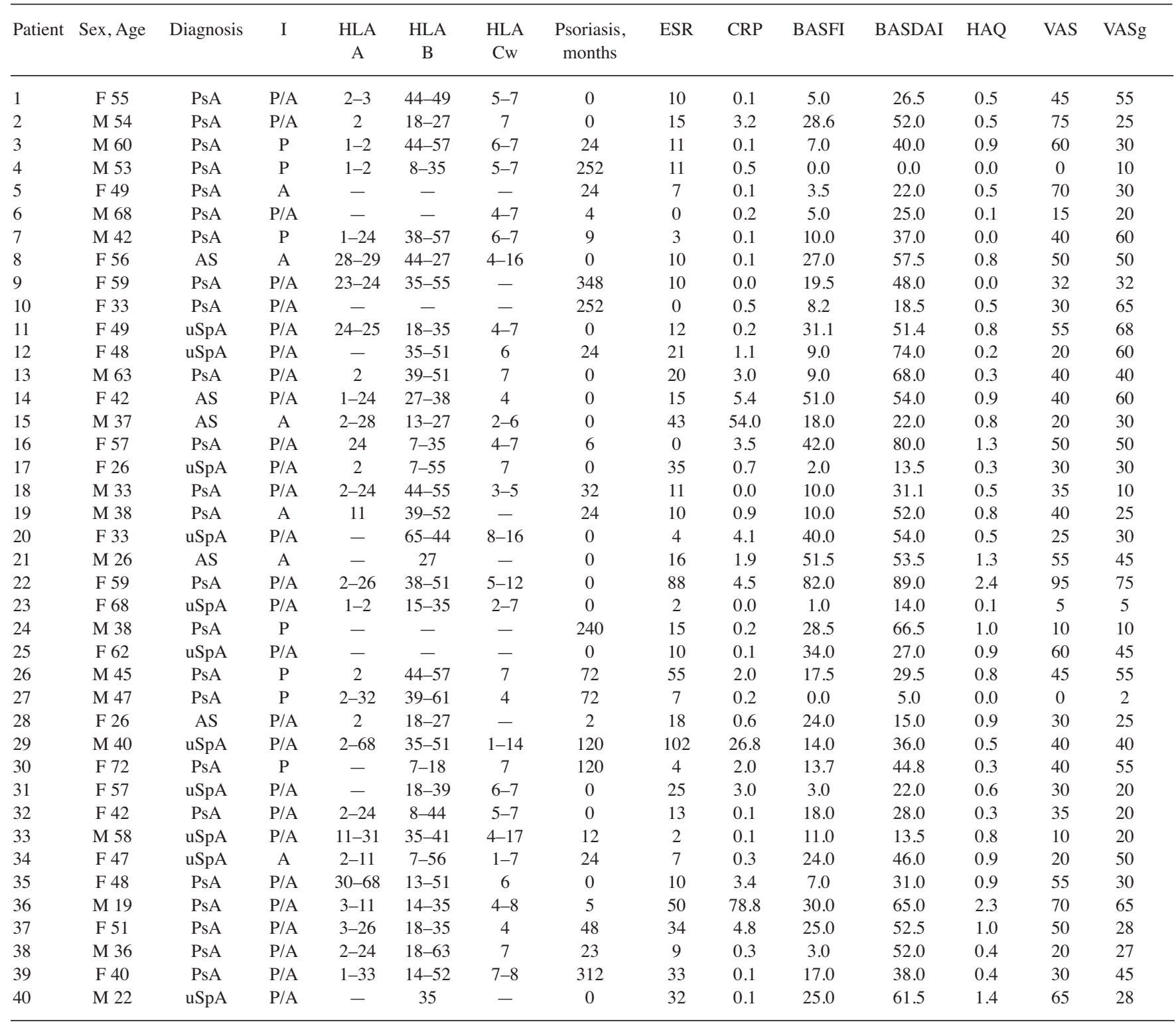

I: involvement; P/A: peripheral/axial; ESR: erythrocyte sedimentation rate (mm/h); CRP: C-reactive protein (mg/dl); BASFI: Bath Ankylosing Spondylitis Functional Index; BASDAI: Bath Ankylosing Spondylitis Disease Activity Index; HAQ: Health Assessment Questionnaire; VAS: visual analog scale for pain; VASg: visual analog scale for health; SpA: spondyloarthritis; PsA: psoriatic arthritis; AS: ankylosing spondylitis.

Two important findings emerging from our study were (1) that $60 \%$ of the newly diagnosed patients complaining about pain or tenderness were indeed affected with PsA; and (2) that ACW involvement was associated with morphological structural alterations, and in particular bone edema with synovial hyperemia and increased capsular structure thickness in the uSpA subset (27.5\% of our patient population), a group in which ACW involvement has not been studied extensively. Another relevant finding was the higher prevalence of ACW involvement in women (55\%). Our results also indicated frequent involvement of the right and left SCCJ (57.5\%) according to the clinical, bone scan, and MRI assessments. A minor yet significant involvement was also observed in sternal joint patients (10\%; Table 2). Analysis of agreement between clinical findings and the 2 imaging procedures (bone scan and MRI) showed a high level of agreement overall for each ACW joint, especially between MRI and bone scans and between clinical findings and bone scans. While there was a lower level of agreement between clinical evaluations and MRI data, the highest level of agreement concerned the sternal joint and sternum (Table 3). Previous reports have not clearly identified what ACW sites are most frequently involved: some studies have shown that SCCJ and sternal joints are similarly affect$\mathrm{ed}^{2,15}$, while others suggest that the sternal joint is affected 


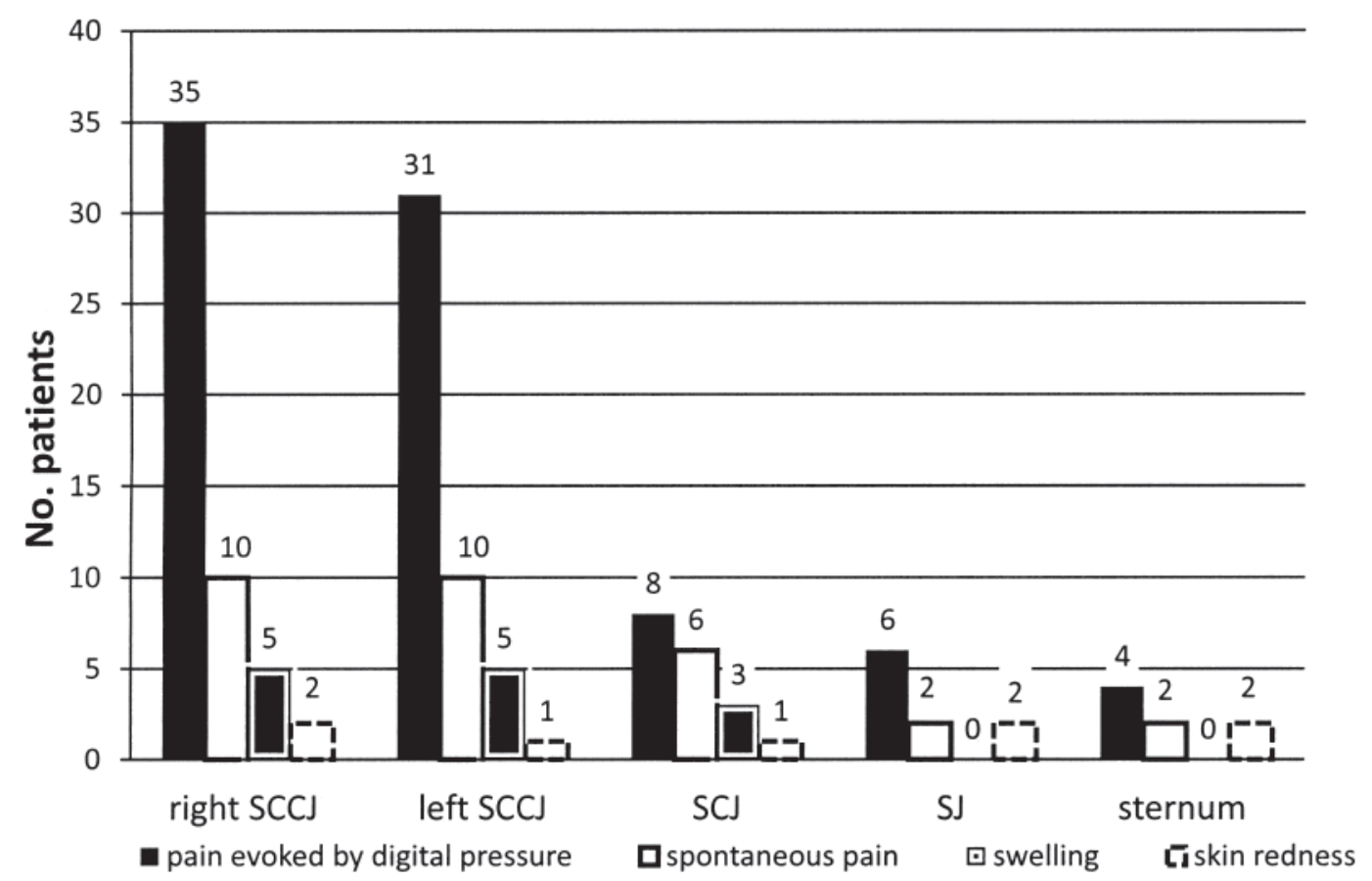

Figure 3. Clinical assessments in anterior chest wall joints. SCCJ: sternocostoclavicular joint; SCJ: sternocostal joints; SJ: sternal joints.

Table 2. Clinical assessment, bone scans, and MRI in anterior chest wall joints.

\begin{tabular}{lccc}
\hline Joint & $\begin{array}{c}\text { Clinical } \\
\text { Involvement }(\%)\end{array}$ & Bone Scan (\%) & MRI (\%) \\
\hline Right SCCJ & $37(87.0)$ & $27(67.5)$ & $19(47.5)$ \\
Left SCCJ & $31(77.5)$ & $21(52.5)$ & $16(40.0)$ \\
Sternocostal & $4(10.0)$ & $5(12.5)$ & $4(10.0)$ \\
Sternal/manubriosternal & $8(20.0)$ & $9(22.5)$ & $4(10.0)$ \\
Sternum & $14(35.0)$ & $14(35.0)$ & $8(20.0)$ \\
Total & $40(100)$ & $40(100)$ & $25(62.5)$ \\
\hline
\end{tabular}

SCCJ: sternocostoclavicular joint; MRI: magnetic resonance imaging. more frequently ${ }^{16,17,18,24,25,26}$, particularly in AS. This is in agreement with findings that inflammatory processes in ACW are similar to those in sacroiliac joints, with regard to the type of disease process and the timing of early development. Older studies described a positive relationship between ACW involvement and disease severity ${ }^{16,17,18}$, whereas more recent findings indicate that it is the first disease manifestation in the uSpA subgroup ${ }^{4,9,19,20}$. In our study, bone scan assessment confirmed ACW involvement in all patients evaluated, even in those with inappreciable symptoms, while MRI results were positive in only $62.5 \%$ (Table 2 ).

Our findings indicate that MRI is a useful tool to study ACW joint involvement as it often confirms diagnosis and provides specific information about disease activity and severity. While bone scan is sensitive, if not specific, to early

Table 3. Agreement between clinical findings and each imaging modality (K values).

\begin{tabular}{lcccrrr}
\hline Joint & \multicolumn{2}{c}{ MRI/Bone Scan } & \multicolumn{2}{c}{$\begin{array}{c}\text { Clinical Evaluation/ } \\
\text { Bone Scan }\end{array}$} & \multicolumn{2}{c}{ Clinical Evaluation/MRI } \\
& $N^{*}$ (total) & $\mathrm{K}$ & $\mathrm{N}^{*}$ (total) & $\mathrm{K}$ & $\mathrm{N}^{*}$ (total) & $\mathrm{K}$ \\
\hline Right SCCJ & $25(40)$ & 0.46 & $31(40)$ & 0.48 & $22(40)$ & 0.23 \\
Left SCCJ & $26(40)$ & 0.56 & $27(40)$ & 0.47 & $21(40)$ & 0.31 \\
Sternocostal & $29(40)$ & 0.72 & $25(40)$ & 0.61 & $32(40)$ & 0.80 \\
Sternal/manubriosternal joint & $27(40)$ & 0.64 & $28(40)$ & 0.68 & $27(40)$ & 0.66 \\
Sternum & $33(40)$ & 0.82 & $37(40)$ & 0.92 & $32(40)$ & 0.80 \\
& & & & & &
\end{tabular}

* Number of patients with concordance of 2 methods (++ and - -). SCCJ: sternocostoclavicular joint; MRI: magnetic resonance imaging; total: total patients studied. 
inflammation, MRI better defines pathological processes and their effects on adjacent structures; it also detects early signs of active disease, outlines the disease processes, and delineates advanced alterations.

The ACW in SpA has not received much attention to date, for a variety of reasons. In clinical practice, patients may mention ACW symptoms, but various explanations for them are possible because there are numerous anatomical structures in that area. During an examination the physician may note the typical signs of tenderness, pain, swelling, or redness, but may not connect these symptoms to joint disorders and may not order appropriate investigations, and even when a simple radiograph is prescribed, little valuable information emerges because uniplanar imaging is unable to visualize ACW joints ${ }^{5}$. More sensitive, although less specific, bone scanning can uncover a general pattern of affected joints, but provides little detailed information on local joint pathology $y^{4,9}$. A multiplanar imaging procedure, MRI can visualize all thoracic structures ${ }^{10,11,12,13,14}$.

ACW involvement is a frequent finding in the early stages of SpA. More than a quarter of 110 patients with recently diagnosed SpA attending our clinic, primarily women, were found to have $\mathrm{ACW}$ involvement. Bone scans and MRI were both found to be useful to investigate these joints. Bone scanning was found to have a higher sensitivity in comparison with other procedures, and although less specific, it identified precocious subclinical joint involvement. MRI was found to

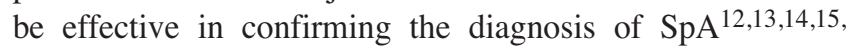
$16,17,18,19,20,26,27$ and in providing information useful for the therapeutic approach, revealing the type, extent, and duration/time of joint involvement.

\section{ACKNOWLEDGMENT}

The authors express their gratitude to Linda Inverso Moretti for help in editing this report.

\section{REFERENCES}

1. Guglielmi G, Scalzo G, Cascavilla A, Salaffi F, Grassi W. Imaging of the seronegative anterior chest wall (ACW) syndromes. Clin Rheumatol 2008;27:815-21.

2. Jurik AG. Seronegative arthritides of the anterior chest wall: A follow-up study. Skeletal Radiol 1991;20:517-25.

3. Scarpa R, Cuocolo A, Peluso R, Atteno M, Gisonni P, Iervolino S, et al. Early psoriatic arthritis: The clinical spectrum. J Rheumatol 2008;35:137-41.

4. Stafford L, Youssef PP. Spondyloarthropathies: An overview. Intern Med J 2002;32:40-6.

5. Ernberg LA, Potter HG. Radiographic evaluation of the acromioclavicular and sternoclavicular joints. Clin Sports Med 2003;22:255-75.

6. Guglielmi G, Cascavilla A, Scalzo G, Salaffi F, Grassi W. Imaging of sternoclavicular joint in spondyloarthropathies and other rheumatic conditions. Clin Exp Rheumatol 2009;3:402-8.

7. Restrepo CS, Martinez S, Lemos DF, Washington L, McAdams HP, Vargas D, et al. Imaging appearances of the sternum and sternoclavicular joint. Radiographics 2009;29:839-59.
8. Louvel JP, Duvey A, Da Silva F, Primard E, Mejjad O, Henry J, et al. Computed tomography of sternoclavicular joint lesions in spondyloarthropathies. Skeletal Radiol 1997;26:419-23.

9. Ramonda R, Zucchetta P, Contessa C, Punzi L. The psoriatic great toe or the psoriatic onycho-pachydermo-periostitis of great toe (OP3gt). Reumatismo 2004;56:282-5.

10. Brossmann J, Stabler A, Preidler KW, Trudell D, Resnick D. Sternoclavicular joint. MR imaging - anatomic correlation. Radiology 1996;193-8.

11. Klein MA, Spreitzer AM, Miro PA, Carrera GF. MR imaging of the abnormal sternoclavicular joint: A pictorial essay. Clin Imaging 1997;21:138-43.

12. Ostergaard M, Poggenborg RP, Axelsen MB, Pedersen SJ. Magnetic resonance imaging in spondyloarthritis - How to quantify findings and measure response. Best Pract Res Clin Rheumatol 2010;24:637-57.

13. Cimmino MA, Innocenti S, Librone F, Magnaguagno F, Silvestri E, Garlaschi G. Dynamic gadolinium-enhanced magnetic resonance imaging of the wrist in patients with rheumatoid arthritis can discriminate active from inactive disease. Arthritis Rheum 2003;48:1207-13.

14. Cimmino MA, Parodi M, Innocenti S, Succio G, Banderali S, Silvestri E, et al. Dynamic magnetic resonance of the wrist in psoriatic arthritis reveals imaging patterns similar to those of rheumatoid arthritis. Arthritis Res Ther 2005;7:R725-31.

15. Jurik AG. Seronegative arthritides of the anterior chest wall: A follow up study. Skeletal Radiol 1991;20:517-25.

16. Jurik AG. Anterior chest wall involvement in seronegative arthritis. A study of the frequency of changes at radiography. Rheumatol Int 1992;12:7-11.

17. Savill DL. The manubrio-sternal joint in ankylosing spondylitis. J Bone Joint Surg Br 1951;33:56-64.

18. Kormano M, Karvonen J, Lassus A. Psoriatic lesion of the sternal synchondrosis. Acta Radiol Diagn 1975;16:463-8.

19. Fourniè B, Boutes A, Dromer C, Sixou L, Le Guennec P, Granel $\mathrm{J}$, et al. Prospective study of anterior chest wall involvement in ankylosing spondylitis and psoriatic arthritis. Rev Rhum Engl Ed 1997;64:22-5.

20. Le Loët X, Vittecoq O. The sternocostoclavicular joint: Normal and abnormal features. Joint Bone Spine 2002;69:161-9.

21. Zochling J, van der Heijde DM, Burgos-Vargas R, Collantes E, Davis JC Jr, Dijkmans B, et al. ASAS/EULAR recommendations for the management of ankylosing spondylitis. Ann Rheum Dis 2006;65:442-52.

22. Weber U, Lambert RG, Rufibach K, Maksymowych WP, Hodler $\mathrm{J}$, Zejden A, et al. Anterior chest wall inflammation by whole body MRI in patients with spondyloarthritis: Lack of association between clinical and imaging findings in a cross-sectional study. Arthritis Res Ther 2012;14:R3.

23. Scarpa R, Altomare G, Marchesoni A, Balato A, Matucci Cerenic M, Lotti T, et al. Psoriatic disease: concept and implications. J Eur Acad Dermatol Venereol 2010;24:627-30.

24. Paker VS, Malhotra CM, Ho G Jr, Kaplan SR. Radiographic appearances of the sternomanubrial joint in arthritis and related conditions. Radiology 1984;153:343-7.

25. Sebes JI, Salazar JE. The manubriosternal joint in rheumatoid disease. AJR Am J Roentgenol 1983;140:117-21.

26. Ory PA, Gladman DD, Mease PJ. Psoriatic arthritis and imaging. Ann Rheum Dis 2005;64 Suppl 2:ii55-7.

27. Raza N, Hameed A, Ali MK. Detection of subclinical joint involvement in psoriasis with bone scintigraphy and its response to oral methotrexate. Clin Exp Dermatol 2007;33:70-3. 